they are bound to the different soil components since their mobility depends on this, as do the mitigation and remediation of contaminated areas.

By means of sequential extractions the hydrogeochemical behavior of metal ions in contaminated soils will be determined. This method selectively extracts metallic ions associated with different soil fractions through sequential utilization of reagents from the least to the most aggressive.

Of interest in this project are the exchangeable ions, bound to oxides/hydroxides of iron and manganese, to carbonates, to organic matter, and to residual binding fractions.

The sequential extraction procedure for determination of heavy metals and their speciation in soils have been developed in the past 20 years. This methodology was introduced by Tessier et al. (1979) and later publications are largely based in this work.

In most of the literature references, the conditions under which the extractions were performed are not completely specified. Also, depending on the soil type and the metals analyzed, the extractions may present difficulties which have to be overcome.

In this study, the selective extraction methods will be chosen, those which are most interesting will be tested, and new methods will be developed.

An experimental station will be built for collecting soil and water samples, monitoring wells and carrying out experiments. In situ monitoring of parameters such as $\mathrm{pH}$, Eh, CE, temperature and alkalinity will also be performed.

This project will contribute to our understanding about important mechanisms of mobility and fixation of metallic ions associated with soils. - (December 14, $2001)$.

\section{MORPHOLOGY OF THE IBIRAQÜERA DUNEFIELD, $\mathrm{SC}^{*}$}

\section{Caroline T. Martinho** and Paulo C.F. Giannini}

Departamento de Geologia Sedimentar e Ambiental, Instituto de Geociências, USP, São Paulo, SP.

Presented by Antonio C. Rocha-CAmpos

The Ibiraquiera beach is located in the municipal district of Imbituba, mid-south coast of the Santa Catarina State. The active dunefield present in this beach possesses parabolic geometry and oblique position to the coastline. It begins with foredunes, that locally appear cut and destabilized by for blowouts. Towards the inte- rior, the dunefield passes into an extensive deflation area. This area is composed by deflation plains, usually vegetated and/or flooded, gegenwalle ridges, trailing ridges and isolated parabolic dunes. The trailing ridges appear as lateral portions of transverse and barchanoid dunes. They are fixed by vegetation and left back while the rest of the dune migrates, forming straight ridges of sand, vegetated in the external part and unvegetated in the internal part. The gegenwalle ridges appear in the deflation plain as small ridges of sand (approximate height of $1 \mathrm{~m}$ ) that possess the identical format of the barchanoid and parabolic dunes' windward limit. They form periodic sequences that record dunefield migration in the deflation area. The parabolic dunes present unvegetated sands in the main advance front (depositional lobe), trailing ridges on both sides with a deflation plain between them. In the internal part of the dunefield the deflation facies disappears, giving place to chains of transverse and barchanoid dunes. They finish in secondary advance fronts contained by the vegetation (precipitation ridges). The whole internal and frontal dunefield borders possess precipitation dunes. In old dunefields totally vegetated now, morphologic features were also recognized such as precipitation dunes and deflation plains.

In Ibiraqüera it is possible to notice that the dunefield started from the north part of the beach and migrated SW, toward the continent. The north section of the beach possesses higher sediment supply than the other sites, seeing that the foredunes in this area are not very well developed, and are buried by small transverse dunes that appear close to the beach.

The characterization of the facies of the Ibiraquiera dunefield allowed to correlate this dunefield to the typical distal or deflation facies association described by Giannini (An Acad Bras Cienc (1998) 70(3): 696). - ( December 14, 2001 ).

\footnotetext{
* Supported by FAPESP 99/05740-3.

**E-mail: ctmartinho@hotmail.com
}

HEAVY METALS CONCENTRATION $(\mathrm{Cr}, \mathrm{Cu}, \mathrm{Ni}$ and Zn) IN BOTTOM SEDIMENTS OF THE EMBU-MIRIM RIVER - SP

Claudia L. Moura ${ }^{1 *}$ and Joel B. Sígolo ${ }^{2} * *$

${ }^{1}$ Programa de Pós-graduação em Geoquímica e Geotectônica, Instituto de Geociências, USP, São Paulo, SP.

${ }^{2}$ Departamento de Geologia Sedimentar e Ambiental, Instituto de Geociências, USP, São Paulo, SP. 